\title{
A Casa do Rio Vermelho: De lugar de memória a lugar literário - uma possibilidade de turismo cultural sustentável em Salvador, Bahia, Brasil
}

\section{Casa do Rio Vermelho: From place of memory to literary place - a possibility of sustainable cultural tourism in Salvador, Bahia, Brazil}

\author{
Juliana Menezes \\ Instituto Federal da Bahia (NEPUC-SB), Instituto de Estudos em Literatura e Tradição (IELT), Centro de \\ Estudos Comparatistas (CEC - FLUL) \\ jumenezes2@hotmail.com
}

\begin{abstract}
Resumo
Este trabalho se propõe a discutir a relação entre o lugar literário e a possibilidade de desenvolver um turismo cultural sustentável, na cidade de Salvador, Bahia, Brasil, dando destaque à casa-museu Casa do Rio Vermelho, última residência do escritor Jorge Amado. Localizada no Bairro do Rio Vermelho, a Casa reúne fotografias, objetos pessoais e obras de arte, que retratam a vida da família Amado, suas viagens pelo mundo e a cultura da Bahia. É considerada um lugar de memória (Nora, 1993) e, também, um lugar literário (Quinteiro \& Baleiro, 2019), por apresentar elementos que possuem significado afetivo, histórico, cultural e literário, atraindo turistas e residentes. Devido à riqueza do acervo e utilização das técnicas e estratégias de interpretação do patrimônio, é um dos lugares mais visitados para aqueles que desejam uma experiência longe da agitação do centro histórico, o Pelourinho, contribuindo para o fortalecimento do turismo cultural sustentável. Neste estudo, foram realizadas análise documental, revisão bibliográfica e observação in loco.
\end{abstract}

Palavras-chave: Casa do Rio Vermelho; lugar de memória; lugar literário; turismo cultural sustentável.

\begin{abstract}
This paper aims to discuss the relationship between the literary place and the possibility of developing sustainable cultural tourism, in the city of Salvador, Bahia, Brazil, highlighting the Casa do Rio Vermelho house-museum, the last residence of the writer Jorge Amado. Located in the neighbourhood of Rio Vermelho, the house offers a collection of photographs, personal objects and works of art, which portray the life of the Amado family, their various trips around the world, and the culture of Bahia. It is considered a place of memory (Nora, 1993) and a literary place (Quinteiro \& Baleiro, 2019), since it presents elements that have meaning from an affective, historical, cultural and literary point of view, attracting tourists and residents. Due to the wealth of its collection and the use of heritage interpretation techniques and strategies, it is one of the most visited places for those who want an experience away from the bustle of the historic centre, Pelourinho, contributing to the strengthening of sustainable cultural tourism in the city. To develop this study, documental analysis, bibliographic review and on-site observation were carried out.
\end{abstract}

Keywords: Casa do Rio Vermelho; literary place; place of memory; sustainable cultural tourism.

Dos Algarves: A Multidisciplinary e-Journal, $37-2020$.

ISBN 2182-5580 @ ESGHT - University of the Algarve, Portugal.

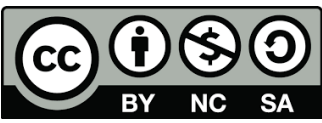

Para citar este artigo: Menezes, J. (2020). A Casa do Rio Vermelho: De lugar de memória a lugar literário - uma possibilidade de turismo cultural sustentável em Salvador, Bahia, Brasil. Dos Algarves: A Multidisciplinary e-Journal, 37, 71-87. doi: 10.18089/DAMeJ.2020.37.5 


\section{Introdução}

A cidade de Salvador, capital da Bahia, no Brasil, é conhecida por seus elementos culturais marcantes, como a música, a gastronomia e a religião. Além disso, também atrai milhares de turistas nacionais e internacionais devido ao característico Carnaval, considerado a maior festa popular do mundo, com seus trios elétricos e famosos blocos. A beleza do conjunto arquitetônico de suas igrejas e os casarios do Pelourinho, centro histórico da cidade, assim como a beleza natural de suas praias, fazem de Salvador um dos principais destinos turísticos do Brasil.

A cidade oferece potencialidades tanto para aqueles que se interessam por sol, praia e festas quanto para turistas interessados em conhecer a história e vivenciar um pouco da cultura baiana. Além disso, a capital da Bahia ainda oferece potencialidades literárias, devido, em sua maioria, às histórias criadas pelo escritor Jorge Amado e imortalizadas em romances como Jubiabá (1935), Capitães da Areia (1937), A morte e a morte de Quincas Berro d’Água (1959), Dona Flor e seus dois maridos (1966), Tenda dos Milagres (1969), dentre outros. Diante de tais potencialidades, o turismo literário em Salvador é uma possibilidade de apresentar a cidade sob uma ótica diferente daquela que geralmente as pessoas conhecem, agregando outro significado a muitos lugares que fazem parte dos roteiros turísticos mais conhecidos, tornando-os também lugares literários. Neste sentido, dentre as potencialidades culturais da cidade, neste trabalho será dado destaque àquelas relacionadas ao escritor Jorge Amado que, além de ter vivido na cidade, foi responsável por boa parte da divulgação do lugar, por ter ficcionalizado muito da vida, dos costumes e da identidade do povo baiano. Sobre o assunto, a antropóloga llana Goldstein (2002) afirma que o repertório do escritor baiano é nutrido por dois pólos: a vivência cotidiana nas ruas de Salvador e o domínio das etnografias produzidas sobre o candomblé e textos científicos sobre folclore, história e problemas raciais. Desta forma, as facetas da Bahia, tais como a paisagem marítima, o cotidiano, a pobreza, as festas, a comida, a capoeira e os cultos afrobrasileiros, fornecem a moldura para a criação literária do autor. Na mesma direção, Simões (2018) argumenta que a significação da obra amadiana se impõe e se amplia com o tempo, uma vez que levou para o mundo a cultura baiana. A autora ainda acrescenta que Jorge Amado transformou-se em ícone da Bahia e a sua obra tornou-se estratégia para a sustentabilidade e desenvolvimento através do turismo.

Devido ao sucesso dos seus romances e consequente projeção no cenário mundial que, segundo Goldstein (2002), deu-se provavelmente por causa da relação do escritor com a cultura popular e o seu poder simbólico na Bahia, muitos turistas têm especial interesse em conhecer a cidade de Salvador e identificar locais históricos habitados pelas personagens ficcionais ou conhecer a casa onde viveu o autor. Dentre outras razões, esse interesse tornou imprescindível a preservação do patrimônio cultural e, como consequência, o poder público formatou atrativos turísticos potencializando a imagem e a recepção do escritor baiano. Como exemplo, é possível citar o Pelourinho, centro histórico da cidade, cenário de alguns dos romances amadianos e o lugar onde se localiza a Fundação Casa de Jorge Amado, uma organização não-governamental que objetiva preservar e divulgar a obra do escritor, além de incentivar a pesquisa sobre o autor, outros autores e sobre a cultura baiana. Ainda no centro histórico, durante as sextas-feiras dos meses de janeiro e fevereiro, acontece o Circuito Jorge Amado, um musical em homenagem ao escritor e sua obra. Durante esse percurso, personagens como Dona Flor, Vadinho, Teodoro, Pedro Archanjo, Gabriela e Tereza Batista 
saltam dos romances e circulam, cantam e dançam pelas principais ruas do Pelourinho. Há ainda a Casa do Rio Vermelho, situada no bairro Rio Vermelho, última morada do casal Jorge Amado e Zélia Gatai, hoje transformada em casa-museu.

Como visto, a capital baiana possui grandes potencialidades turísticas, por isso políticas públicas têm sido traçadas para a dinamização do turismo e, simultaneamente, para valorizar seus recursos naturais e culturais. Segundo Guerreiro (2005), desde os anos 80 do século passado tem-se investido na transformação dos bens culturais em atrativos turísticos, devido ao interesse nacional pelas peculiaridades da cultura da Bahia. De acordo com a autora, o aumento do interesse pela cultura baiana deu-se principalmente devido à imagem construída por literatos, cineastas e músicos. Desta forma, os gestores turísticos, cientes da capacidade de transcendência da produção cultural da cidade, disseminada nacionalmente nos anos 60 e 70, procuraram transformar as particularidades da cultura local em atrativos turísticos, investindo assim no turismo cultural.

O investimento no turismo cultural, compreendido como o tipo de turismo no qual as pessoas buscam consumir cultura quando viajam (Richards, 2000), acompanha as tendências do mundo globalizado, uma vez que caminha em paralelo com a homogeneização das identidades locais e com o reforçamento dessas identidades. Sobre o assunto, Hall (1992) afirma que a globalização explora a diferenciação local e, por isso, seria preciso pensar numa nova articulação entre "o global” e "o local”. A globalização, nesse sentido, iria produzir novas identificações "locais". Tais identificações estariam relacionadas à valorização de traços e características particulares que distinguem cada região, tendo como base as suas raízes e tradições, recuperando, assim, o sentido de sua história. Ao mesmo tempo, essas identificações teriam como referência as características globais da pós-modernidade, que envolvem relações culturais diversas. Assim, o turismo cultural apresenta-se como uma possibilidade de potencializar a cultura local frente ao mundo globalizado já que oferece ao turista uma série de elementos que particularizam um local, acrescentando valor à experiência turística e, ao mesmo tempo, dinamizando a economia.

Nesse contexto, tem crescido também o interesse pelo turismo literário, uma "modalidade do turismo cultural que se desenvolve em lugares relacionados com os acontecimentos dos textos de ficção e com a vida dos autores. Um novo turismo cultural que implica o relacionamento da ficção no mundo real" (tradução da autora), como afirmam Magadán-Díaz e Rivas García (2012: 10). Nessa interseção entre cultura e turismo, Simões (2018) considera que a literatura aparece como uma forma de conciliar o estético com o turismo, fazendo ressaltar a importância da cidade como cenário ficcional e como "produção de localidade", expressão utilizada no sentido dado por Appadurai (1996). A autora ainda salienta que é possível pensar em formas de se valorizar a literatura, compreendendo a atividade turística como uma estratégia de fazer interagir o global e o local, evitando cair no aspecto homogeneizador do global. Assim, lugares que possuem algum tipo de relação com autores e/ou com sua obra passam a fazer parte de roteiros turísticos, dando visibilidade aos elementos culturais ensejados através da associação com a literatura e atraindo o interesse dos turistas que, ao visitá-los, os ressignificam, transformando-os em lugares literários.

Nessa perspetiva, com o objetivo de discutir a relação entre o lugar literário e a possibilidade de desenvolver um turismo cultural sustentável, este estudo destaca a Casa do Rio Vermelho, uma vez que é um dos lugares mais visitados por aqueles que desejam uma experiência longe da agitação do centro histórico, contribuindo para o fortalecimento do turismo cultural de Salvador. A Casa reúne um acervo de objetos pessoais que representam as 
vivências e as memórias do escritor Jorge Amado, assim como reúne um manancial de elementos culturais, sociais e históricos que particularizam a Bahia. Tais elementos contribuem para a compreensão da identidade baiana e para a valorização da cultura local, além de servirem de atrativos intensificadores do turismo cultural sustentável da cidade. Para desenvolver este estudo, foram realizadas análise de documentos, revisão bibliográfica e observação in loco.

\section{A casa do Rio Vermelho: Se for de paz, pode entrar}

A Casa do Rio Vermelho foi residência de Jorge Amado e Zélia Gatai por aproximadamente quarenta anos e o lugar onde o casal recebia visitas de amigos ilustres ligados à cultura e ao pensamento crítico do século XX. Ocupa mais de dois mil metros quadrados, incluindo o jardim onde estão depositadas as cinzas do casal, e em seus diversos ambientes estão expostos objetos pessoais que não só contam a história de seus moradores naquele lugar ou em viagens pelo mundo, mas que traduzem muito da cultura baiana. Partindo da ideia de lugar como um local significativo (Cresswell, 2015), a Casa, que possui significado tanto afetivo quanto cultural, é aqui compreendia como um lugar de memória no sentido dado por Pierre Nora (1993), que o entende como um lugar cuja razão de ser é impedir o esquecimento e revestir os lugares de sentido, tornando-os apaixonantes. O conhecimento de como a casa foi construída, mobiliada e decorada ratifica essa ideia, uma vez que cada canto, objeto, cômodo e fotografia está repleto de significado afetivo e cultural e representa as vivências, lembranças, assim como as crenças e ideologias de seus moradores.

Após anos morando fora da Bahia e do Brasil, o casal Jorge Amado e Zélia Gatai realiza o sonho de viver em Salvador. Em 1960, com o dinheiro da venda dos direitos para adaptação cinematográfica do livro Gabriela Cravo e Canela (1958), Jorge Amado comprou um terreno e nele construiu a tão sonhada casa na Rua Alagoinhas, número 33, no bairro Rio Vermelho, em Salvador, Bahia. Segundo declaração do próprio escritor, "a casa não se parece com nenhuma outra, é única" (Amado, 1999: 16). Assim, em 1963, a família Amado mudou-se para o lugar e, aos poucos, foi compondo seu lar, recheando-o com objetos, fotografias, obras de arte, presentes, miniaturas e peças de artesanato. Ao longo dos anos, a casa foi sendo mobiliada, decorada, habitada, preenchida de vida, de lembrança de vida, criando assim um significado simbólico e afetivo. De acordo com Chaves (1999), a morada de Jorge e Zélia resultou com o tempo em uma casa pregnante, prenhe, repleta, plena, cheia e pejada de objetos que não são comuns a qualquer colecionador. São objetos, adquiridos pelos moradores ou oferecidos por amigos, que possuem algo de expressão plástica, criatividade e utilidade e que estão implantados, incorporados, fixados em cada pequeno espaço da casa, posicionados para despertar a curiosidade e excitar a imaginação, como se fosse um mundo mágico. "Um mundo dentro de outro mundo. Único”, afirma o arquiteto (Chaves, 1999: 76). A casa, de fato, é única, não só por causa da arquitetura e por ter sido o local onde Jorge Amado escreveu muitos dos seus livros, mas porque simboliza tudo que o casal vivia e acreditava. Desta forma, pode-se pensar que, com o passar do tempo, Jorge Amado e Zélia Gatai foram tecendo histórias, atando laços afetivos naquele lugar que passou a ser, para eles, talvez o centro do mundo, um lugar recheado de afeto, construído para acolher, abrigar a família e os amigos. Um paraíso, ambiente amoroso e criativo, como declarou Paloma Amado, filha do casal, no texto de abertura do folheto distribuído no museu (Amado, 2014). A casa, pensada nessa perspectiva, 
pode ser entendida como o espaço sagrado no sentido dado por Eliade (1992). Segundo este autor, toda a casa é santificada porque reflete uma imago mundi, e todo Mundo é criação divina. Para Eliade, "o verdadeiro mundo" se encontra sempre no "meio", no "centro", pois "o centro é justamente o lugar onde se encontra uma rotura de nível, onde o espaço se torna sagrado, real por excelência” (1992: 44). A casa real, sonhada por Jorge Amado e sua esposa, era exatamente assim: um grande lar que a todos abrigava, o centro do mundo.

As obras de arte espalhadas harmoniosamente pela residência retratam a cultura baiana e, particularmente, a religiosidade do escritor. Quadros de grandes pintores como Picasso, Di Cavalcante e muitos outros revestem as paredes da sala e representam o gosto do escritor pela arte. A casa, vista por essa perspectiva, confirma a ideia de lugar de memória, uma vez que esses lugares abrangem não só as edificações, mas todos os documentos de cultura, isto é, toda a produção estética, incluindo a literatura, as artes plásticas, a música, além da imprensa e da iconografia (Nora, 1993). Para o historiador francês, os lugares de memória são aqueles que possuem simultaneamente em sua essência os aspectos material, simbólico e funcional. Material porque possui um conteúdo demográfico; funcional porque ativa a lembrança e incentiva a sua transmissão; e simbólico porque representa um acontecimento vivido por uma minoria. Não há dúvida que aquela casa reúne tais aspectos, pois abriga objetos que pertenciam à família Amado, tais objetos ativam a memória e representam as vivências de seus moradores. Diante disso, nota-se que Jorge Amado fez da sua casa não só o lugar para viver, transformou-a num lugar no qual havia uma simbiose entre vida, arte e memória, como se fosse uma confirmação daquilo que tinha como mote: "fiz de minha vida e minha obra uma coisa única", como declarou em seu discurso de posse na Academia Brasileira de Letras (Amado, 1961, manuscrito 482: 7, citado em Goldstein, 2002: 111). Tal constatação coaduna com as palavras de Hendrix (2012), que afirma que, para alguns autores, um lugar para morar é também uma forma de expressão e lembrança, além de servir como moldura para sua arte, uma ferramenta que contribui para a produção da sua literatura. Tudo isso atribui à casa um valor histórico, cultural e afetivo.

De acordo com Tude de Sá (2018: 223):

a casa da Rua Alagoinhas, 33 traz as marcas dos afetos, das estéticas, das crenças, ideologias, do capital social e cultural tecido e construído por Jorge Amado. A casa é povoada de obras de arte de artistas baianos, brasileiros e de fora do país, repleta de objetos artesanais e de mobiliário que, registrados e representados nas fotografias, podem ser considerados, também, como uma fonte documental de memória da produção artística e cultural da Bahia de um determinado tempo da sua história.

Diante de tamanha riqueza, após a morte de Jorge e Zélia, a casa, lugar de memória, foi reformada pela Prefeitura Municipal de Salvador, numa intervenção que contou com a participação da Fundação Casa de Jorge Amado, da família do casal e do arquiteto e cenógrafo Gringo Cardi, que assumiu a curadoria do museu. Desta forma, atendendo ao desejo do casal, foi reconfigurada e transformada em casa-museu Casa do Rio Vermelho (Figuras 1, 2 e 3) aberta à visitação desde 2014, para que outras pessoas pudessem tomar conhecimento de todo seu valor simbólico. Em consonância com as palavras de Emery (2012: 212), que afirma que "as casas dos escritores fornecem o acesso à vida dos escritores por meio de um benéfico facsímile, construído num determinado tempo e baseado numa interpretação de artigos de jornais, biografias, livros de memória, críticas literárias e fotografias" (tradução da autora), a vida do escritor baiano pode ser conhecida numa reconstrução que teve por base a 
interpretação de documentos, fotografias e memórias da família. Para o filho do casal de escritores, João Amado, o museu significa compartilhar com as pessoas as emoções vividas pela família e uma história de amor que durou mais de 50 anos (Pitombo, 2014). Assim, passa de casa, lugar de memória, para Casa, lugar literário, ao receber também um valor literário por ter sido morada de um dos escritores brasileiros mais conhecidos mundialmente e atrair o interesse de turistas, sendo possível, desta maneira, a preservação e valorização de traços identitários da cultura local. Isso ratifica as palavras de Nora (1993: 13) quando afirma que "os lugares de memória nascem e vivem do sentimento de que não há memória espontânea, que é preciso criar arquivos, que é preciso manter aniversários, organizar celebrações, [...] porque essas operações não são naturais". Era preciso, assim, manter vivo todo o valor simbólico daquele lugar.

Figura 1. Fachada da Casa

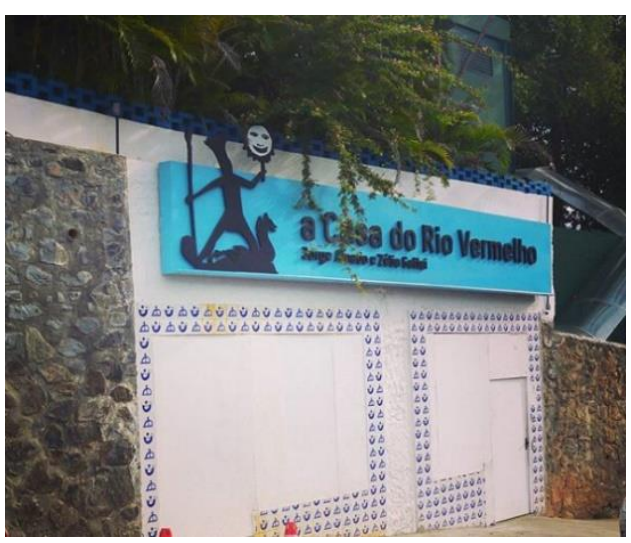

Fonte: www.instagram.com/casadoriovermelho.

Figura 3. Placa de cerâmica colocada na entrada da residência

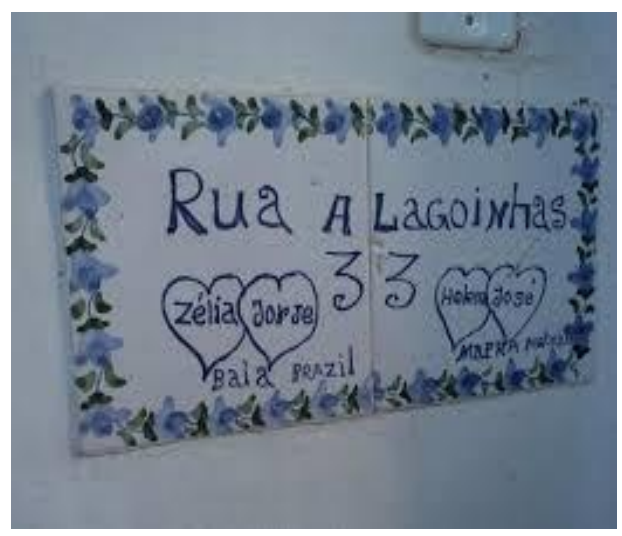

Fonte: Tripadvisor.com.
Figura 2. Jardim e varanda

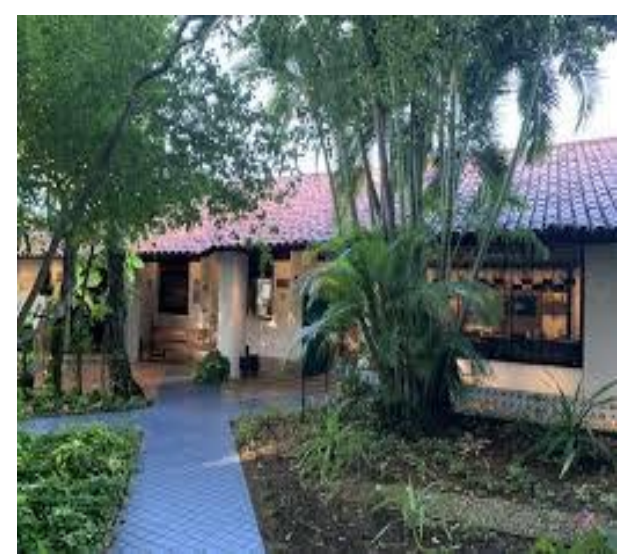

Fonte: diariodesalvador.com.

Figura 4. Tapete na entrada da Casa

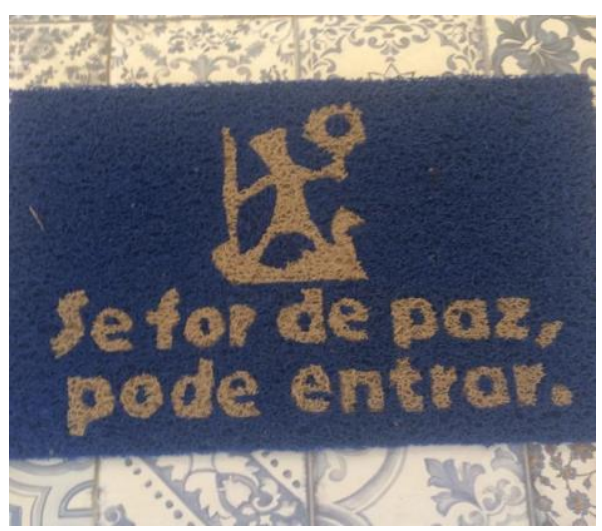

Fonte: Crédito fotográfico Juliana Menezes. 
A mensagem no tapete de entrada da Casa (Figura 4), "Se for de paz, pode entrar", juntamente com a imagem de Oxossi', santo orixá do escritor e logotipo do local, convidam o visitante a adentrar o lugar e conhecer o patrimônio cultural material e imaterial que o compõe. Assim, conhecer a casa significa não só tomar conhecimento da intimidade da família Amado, mas também conhecer personagens, cenas e elementos culturais marcantes que fazem parte da obra do escritor e que também particularizam a Bahia. De acordo com Quinteiro e Baleiro (2019), esse tipo de conhecimento funciona como um protocolo de leitura do espaço, atribuindo-lhe significado, viabilizando a sua concretização e a sua configuração como lugar literário. Para as autoras, lugar literário é "uma porção do espaço que é vivida por um sujeito com a mediação da literatura (do seu texto e/ou do seu autor). O literário surge neste contexto como um elemento que ressignifica os lugares e consequentemente lhes acrescenta valor turístico" (Quinteiro \& Baleiro, 2019: 82). A diversidade de elementos culturais expostos ajuda a compreender a experiência como uma visita a "[...] lugares mistos, híbridos e mutantes, intimamente enlaçados de vida e de morte, de tempo e de eternidade; num espiral do coletivo e do individual, do prosaico e do sagrado, do imóvel e do móvel", revestido de aura simbólica (Nora, 1993: 22). Durante a visita, por meio de técnicas e estratégias da interpretação do patrimônio, os personagens, os cheiros, as cores, as danças e crenças da Bahia saltam das páginas dos livros, povoam o lugar e, de certa forma, sumarizam a vida do escritor, proporcionando ao visitante uma apaixonante experiência turístico-cultural.

\section{Turismo cultural e sustentabilidade na Casa do Rio Vermelho}

O turismo cultural vem adquirindo um crescimento considerável, em consequência do grande interesse do turista em compreender a cultura e a história de lugares diferentes, assim como conhecer hábitos e costumes de outros povos (Lage \& Milone, 2000). Conforme dados da Organização Mundial de Turismo (OMT), o turismo cultural representa 37\% do turismo global e seu crescimento acompanha as tendências do mundo globalizado, assim como o crescente aumento da atividade turística em si, uma das principais atividades econômicas da atualidade. Sobre o assunto, Richards (2009: 25) afirma que o turismo cultural tem sido considerado a área de maior crescimento do turismo como um todo e, cada vez mais, tem sido tomado como a maior área de desenvolvimento de produto pelos destinos turísticos em busca de diversificação. Esse crescente interesse, entretanto, implica em um dos grandes desafios desse segmento turístico no futuro que é assegurar a sua sustentabilidade. Segundo o autor (2009: 29), a maior parte das pessoas que visitam as atrações culturais não têm necessariamente um alto grau de interesse em cultura per se. Como consequência, a cultura torna-se integrada a um sistema de consumo de lazer que é oferecida a consumidores apenas como mais um produto para ser consumido. Em tais circunstâncias, há um perigo de que o desenvolvimento do turismo cultural acabe por causar danos aos recursos culturais que atraíram os turistas num primeiro momento.

Desta forma, para que a cultura não seja utilizada apenas para atender às solicitações de consumo, provocando a sua banalização, se faz necessário acrescentar a este tipo de atividade

\footnotetext{
${ }^{1}$ Divindade das religiões africanas, "orixá das matas, da caça e, por extensão, da busca, da procura, da pesquisa" (Póvoas, 1989: 82).

2 "Nome genérico das divindades dos negros nagôs que personificam as forças da Natureza, embaixadoras entre os homens e o Deus Supremo e encarregadas do equilíbrio de todo o sistema cósmico. Anjo da guarda; encantado; invisível; santo" (Póvoas, 1989: 182).
} 
turística o caráter da sustentabilidade, no sentido de se buscar alternativas capazes de contribuir para o desenvolvimento, promover o bem-estar das populações, preservar os bens culturais para as gerações futuras, gerar benefícios para a comunidade e afirmar a identidade local (Bissoli, 1999). Tal cuidado pode fazer com que, neste tipo de experiência, os bens culturais sejam importantes não porque podem ser comercializados como produto turístico e sim por sua significação simbólica.

Com base em tais considerações, a Casa do Rio Vermelho pode ser compreendida como uma possibilidade de desenvolvimento do turismo cultural sustentável, na medida em que apresenta seus bens simbólicos de maneira viva e desloca o turista, cujo "olhar está direcionado para certos objetos e características extraordinárias que distinguem o lugar/paisagem" (Urry, 1996: 140), para zonas pouco visitadas. Na verdade, a Rua Alagoinhas, no Bairro do Rio Vermelho, talvez não fosse conhecida pelos turistas, caso não existisse o número 33, a Casa do Rio Vermelho. Desta forma, uma vez que a Casa é aqui entendida como lugar literário, pode-se afirmar que, neste caso, a literatura é "uma possível potencializadora da sustentabilidade, imprescindível às dinâmicas das identidades culturais e às ações de turismo", como afirma Simões (2018: 13). Nesse raciocínio, nota-se que, para além de dar visibilidade à cultura local, principalmente aquela ensejada pela literatura de Jorge Amado, valorizando-a, a Casa apresenta-se como uma possiblidade de gerar conhecimento e de motivar a leitura, oferecendo não só aos turistas como a residentes, principalmente grupos de estudantes, uma conexão entre o passado e o presente, gerando ideias para se projetar o futuro, contribuindo para a formação do cidadão. $O$ uso das técnicas e estratégias da interpretação do patrimônio é um dos fatores que facilitam essa disseminação do conhecimento e a preservação dos valores culturais, dando oportunidade de satisfazer a curiosidade do turista ao ser colocado perante traços da cultura baiana. Por outro lado, a interpretação do patrimônio contribui para a afirmação da identidade da comunidade, quando os residentes, ao visitarem o local, se reconhecem em alguns dos elementos culturais retratados ali.

Conforme Tilden (2007: 35), "a interpretação é uma atividade educativa que objetiva revelar significados e inter-relações mediante o uso de objetos originais, experiências em primeira mão e ilustrações, ao invés de simplesmente comunicar informações factuais" (tradução da autora). Além disso, a interpretação deve provocar a curiosidade e enriquecer a mente e o espírito humanos. É nessa perspectiva que o turismo cultural, aliado aos critérios da sustentabilidade social, cultural, ecológica e econômica, pode ser um meio de desenvolvimento sustentável. Desta forma, é possível articular as três ecologias propostas por Guattari (2001) - ecologia ambiental, ecologia social e ecologia mental - uma vez que as novas práticas ecológicas têm por objetivo reapreciar o trabalho humano em função de valores diferentes daqueles do rendimento e do lucro, tornando os territórios existenciais habitáveis por um projeto humano. $\mathrm{O}$ autor apresenta uma preocupação com o mundo que prioriza o lucro econômico e as rápidas transformações técnico-científicas que provocam o desequilíbrio ecológico e ameaçam a vida humana. Diante disso, sugere novas formas do ser humano se relacionar com o meio ambiente (ecologia ambiental), com a sociedade (ecologia social) e com a sua subjetividade, evitando a manipulação e a uniformização midiáticas (ecologia mental), em busca do equilíbrio ecológico e práticas sociais baseadas na ética. De acordo com Guattari (2001), a articulação entre essas três ecologias seria a saída da crise do mundo capitalista. Tais ecologias deveriam ser concebidas como sendo um processo contínuo de ressingularização, 
em que os indivíduos se tornariam, a um só tempo, mais solidários e cada vez mais diferentes. O mesmo processo de ressingularização deveria acontecer com as escolas, as prefeituras, o urbanismo e com o turismo, que valorizariam outras práticas e modos de ser e agir baseados na sustentabilidade ecológica e social. Em consonância com essas ideias, nota-se que os valores importantes para o funcionamento da Casa do Rio Vermelho vão muito além do valor de consumo. Na Casa busca-se a valorização da arte, da cultura e da memória de seus moradores, conjugando rentabilidade econômica com rentabilidade social e educativa, tal como sugere Pérez (2009). O pagamento de uma quantia de vinte reais (cerca de três euros e meio) para ter acesso ao seu interior, além do café e da loja contribuem para a sustentabilidade financeira do museu. Entretanto, a maneira com que os bens culturais são dispostos e apresentados ao público salientam o verdadeiro valor do lugar, tornando-o apaixonante, como é possível conferir nos comentários de visitantes em um site de avaliação de experiências turísticas:

Um lugar imperdível, lindo, cheio de cultura. Lá dentro nem vi o tempo passar, me emocionei, fiquei sem palavras, saí apaixonada por Jorge Amado e sua mulher Zé (como ele a chamava carinhosamente). Saí de lá cheia de paz no coração!

Uma viagem ao tempo que o Brasil tinha apreço por cultura, por intelectualidade e brasilidade. Um mergulho na intimidade e na vida do casal Jorge e Zélia. Parece que a qualquer momento Jorge vai aparecer na sala pra te receber. Inesquecível. (TripAdvisor, 2019)

Nesse raciocínio, pode-se afirmar que as técnicas e as estratégias da interpretação do patrimônio podem se tornar um meio para se alcançar a sustentabilidade do turismo cultural, fazendo com que turistas e comunidade não só apreciem, mas também compreendam, aprendam e encantem-se com um lugar, incentivando, com isso, a preservação e a valorização de seu patrimônio. Além disso, no caso específico da Casa do Rio Vermelho, assim como em outras casas de escritores, podem ainda despertar o desejo de ler os livros escritos por seus moradores. Segundo Padró (1996, apud Pérez, 2009), um dos traços da interpretação é exatamente a interligação com o desenvolvimento sustentável ao mesmo tempo que oferece ao visitante uma série de vivências significativas que lhes permitem ver, sentir, compreender, reviver histórias e situações por meio de diferentes técnicas, desenvolvendo, com isso, produtos e serviços baseados na conservação do patrimônio. Desta forma, diversas estratégias e técnicas da interpretação podem ser usadas a depender do perfil cultural e ambiental do lugar, dos recursos humanos e financeiros disponíveis e do público alvo que se pretende atingir. As estratégias podem incluir trilhas e itinerários sinalizados, cursos de treinamento de guias, publicações de mapas ilustrados e folhetos para que o turista possa se orientar durante a visita, montagem de centros de visitantes e de informação, e museus que oferecem objetos, acervos e podem contar a história do lugar, numa perspectiva tanto histórica quanto cultural e literária. Essas estratégias são utilizadas por meio de um intérprete e/ou de técnicas que valorizam o patrimônio e a experiência do turista (Murta \& Goodey, 1995), construindo uma narrativa carregada de significado. Para Emery (2012), esse tipo de narrativa é especialmente importante para as casas dos escritores porque ao reunir vários elementos que atribuem significado aos objetos, determina e controla como o público as compreende, podendo gerar uma resposta emocional. Desta forma, as casas não correm o risco de parecerem exibições "frias" e "sombrias" sobre determinada época, como aconteceu com o 
quarto de Proust no Musée Carnavalet e muitos outros, ao invés de lares cheios de vida e histórias de seus residentes.

As técnicas da interpretação dão "vida" ao patrimônio, pois são utilizadas linguagens diferentes para a sua promoção. Os meios e técnicas da interpretação são divididos em três categorias distintas. A interpretação ao vivo é uma técnica que pressupõe um ator ou um guia preparado para apresentar a essência do lugar através de contação de histórias, casos, canções, demonstrações e representações de trechos de romances, excursões a pé ou de qualquer outro meio de transporte, dependendo do objetivo e do tema da interpretação. Outra técnica de interpretação diz respeito aos textos impressos que incluem mapas ilustrados, guias e roteiros turísticos, folhetos e cartões postais. Deve-se ter cuidado com o conteúdo informativo do material impresso, que deve servir para a publicidade das atrações, despertar a curiosidade, dar informações verdadeiras sobre o lugar ou fazer referência ao texto literário. Na última categoria, interpretação com base no design, estão incluídos os painéis, as placas e os letreiros que devem conter um texto curto, criativo e significativo com grafia legível e clara e ilustrações que facilitam a compreensão da história do lugar, do autor ou do texto literário. Desenhos, fotografias, gravuras e pinturas são meios eficazes de comunicação. Ainda dentro dessa categoria, encontram-se exposições de objetos e documentos, modelos e reconstruções que vão desde miniaturas e maquetes a cópias de figuras humanas em tamanho normal; reconstrução do passado para apreciação passiva, através de cenário de época e diversos meios interpretativos; meios animados de exibição que compreendem instrumentos mecânicos e eletroeletrônicos, que introduzem som, luz, cheiro e movimento, tornando a exibição o mais real possível, despertando o interesse e facilitando a comunicação entre os visitantes (Murta \& Goodey, 1995).

A utilização dessas estratégias e meios interpretativos não só torna a comunicação eficaz, como também constrói uma narrativa que revela sentidos, provoca a curiosidade, valorizando, assim, o patrimônio e a experiência do turista. Conforme Murta e Goodey (1995), a interpretação do patrimônio cumpre uma dupla função de valorização. Valoriza não só a experiência do visitante, ao conhecer patrimônios preservados e interpretados para a sua melhor compreensão, valoriza, também, o próprio patrimônio, transformando-o em um recurso turístico.

Os estudos de turismo, na perspectiva da interpretação do patrimônio, indicam que para que turismo e cultura tenham uma convivência eficaz, portanto sustentável, é necessário que haja um plano interpretativo. O objetivo desse planejamento é ordenar as ações do ser humano sobre o ambiente, visando a minimizar a sua degradação e estimular a implantação adequada de serviços e equipamentos turísticos de maneira que revelem o lugar de forma significativa. De acordo com Murta e Goodey (1995), para a elaboração de um plano interpretativo é preciso seguir três etapas essenciais. A primeira delas conduz ao inventário e registro de recursos, temas e mercados. O desenho e a montagem da interpretação é o segundo passo e, por fim, faz-se a gestão e a promoção do bem patrimonial. Assim, é possível apresentá-lo, promovê-lo e atualizá-lo como marco importante e atrações turísticas. Além disso, conforme assevera Veverka (2018), é preciso ter as metas e os objetivos muito bem definidos, pois são considerados a chave para o sucesso de qualquer plano interpretativo, uma vez que fornecem a direção e os conteúdos a serem utilizados. Dessa forma, o autor sugere três categorias de objetivos: objetivos educativos, que correspondem àquilo que o visitante precisa conhecer sobre o lugar; objetivos emocionais, relacionados àquilo que o visitante pode 
sentir e os objetivos comportamentais, que se referem àquilo que o visitante pode fazer. Tais categorias, utilizadas em conjunto, facilitam a escolha das informações e ajudam a decidir a melhor forma de transmiti-las ao visitante, de maneira que prenda a atenção, estimule a curiosidade, podendo gerar atitudes de respeito e preservação do patrimônio. Esse procedimento ratifica o pensamento de Tilden (2007), um dos precursores no assunto, que afirma que o principal objetivo da interpretação não é a instrução, mas sim, a provocação, a estimulação e a sedução.

O planejamento interpretativo deve passar por uma vontade política e envolver a decisão de todos aqueles que estão empenhados no desenvolvimento desta atividade: empresas privadas, organizações públicas, representantes comunitários, agentes institucionais, gestores de turismo e o Estado. Sobre o assunto, Murta e Albano (2002) afirmam que o processo de interpretação baseado na comunidade responde à necessidade do planejamento municipal que é proteger e desenvolver um sentido de lugar, de transmitir seus valores, sua ecologia e sua história às novas gerações. O planejamento interpretativo estimula a capacitação adequada para assegurar o envolvimento local nos novos rumos da economia, estimulando a ação conjunta dos poderes públicos e da iniciativa privada. Esse seria chamado de planejamento participativo, cuja finalidade é envolver toda a comunidade para determinar os objetivos e estabelecer a melhor forma para alcançar os resultados pretendidos. Dessa maneira, a comunidade teria possibilidade de compreender o presente através do conhecimento de sua história, da sua literatura, de suas lendas e origens. Para isso, poderiam ser promovidos encontros e reuniões junto às escolas, às associações de bairros, aos clubes de terceira idade e às associações comerciais e industriais, com o propósito de motivar a valorização do patrimônio cultural, dos hábitos, dos costumes e das tradições (Moletta \& Goidanich, 2001).

No caso específico da Casa do Rio Vermelho foi possível constatar que houve a participação tanto das instituições públicas quanto privadas. A comunidade, mesmo não sendo envolvida no processo de planejamento da casa-museu, sente-se orgulhosa ao falar sobre o lugar e sobre o escritor, o que pode ser notado na satisfação dos funcionários, assim como dos residentes que visitam o local.

De acordo com Lucas (2003), a comunidade, quando bem informada, é capaz de valorizar a sua cultura e o seu patrimônio, preservando-o para as gerações futuras. A autora ainda afirma que, quando os moradores locais percebem o valor que os turistas atribuem àquilo que estão indo visitar, em algum aspecto de suas tradições ou paisagens, passam a olhar de maneira diferente aquilo que normalmente passaria despercebido. Assim, esses moradores desenvolvem um sentimento de orgulho pelo legado e desejam passá-lo para as gerações futuras. Nessa mesma direção, Quinteiro e Baleiro (2019) afirmam que as experiências e produtos de turismo literário contêm um forte potencial educativo para a comunidade local, "para aumentar os rendimentos e a educação, preservando simultaneamente a cultura tradicional e protegendo o meio ambiente natural" (Tuan-Anh et al., 2016: 177, citado em Quinteiro \& Baleiro, 2019: 45). Isso fomenta também a afirmação da identidade do povoanfitrião ao mesmo tempo que promove o seu bem-estar econômico.

É nesse contexto que a ideia de desenvolvimento do turismo cultural sustentável reforça a necessidade de um planejamento baseado nos princípios da interpretação do patrimônio, visto que a interpretação investe no bom relacionamento entre morador e visitante, ampliando a participação da comunidade na atividade turística de forma que contribua para o desenvolvimento de um turismo no qual as paisagens naturais e culturais são usufruídas no 
lugar, ao invés de serem consumidas apressadamente, como algo descartável e substituível (Murta \& Albano, 2002).

Tais ideias sobre turismo cultural sustentável podem ser associadas ao turismo literário, uma vez que a literatura, utilizada como recurso, pode suscitar políticas que fomentem a valorização de diferentes expressões culturais e a dinamização da economia local. Segundo Simões (2018), as manifestações culturais expressadas pela literatura são mobilizadoras dos trânsitos que, se operados com sustentabilidade, asseguram a valorização do estético e promovem o desenvolvimento das comunidades.

A observação na Casa do Rio Vermelho permitiu verificar a presença de técnicas e estratégias interpretativas eficientes e de qualidade que atribuem significado à Casa, tanto do ponto de vista literário quanto cultural e histórico. A principal delas é a interpretação ao vivo com a presença de um guia intérprete, um mediador cultural que, por meio de suas informações, constrói a forma de olhar de determinado lugar, atribuindo-lhe sentido (Pérez, 2009). Com o auxílio da interpretação com base no design, que engloba as placas, painéis, exposições de objetos, projeção de imagens, filmes e depoimentos, o guia "corre a casa", como se diz no falar baiano (Amado, 2014), conduzindo o visitante para cada cômodo ao mesmo tempo que narra a história do lugar, fatos marcantes da vida dos moradores, salientando curiosidades sobre os objetos e sobre a rotina da casa, permitindo que a magia do lugar contagie os visitantes.

O périplo começa pela sala de estar, local onde o guia chama a atenção para a grande mesa de jantar que Jorge Amado costumava utilizar para fazer as refeições e escrever (Figura 5). Outros móveis do casal, além de objetos de arte e um baú que abriga livros do escritor, livros de arte e de diversas áreas que serviam de fonte de pesquisa para compor a obra do autor (Figura 6) compõem esse primeiro cômodo. Os quartos são dedicados à projeção de fotos e depoimentos de amigos que se hospedaram na casa, filmes de artistas lendo trechos das obras, ilustrações dos livros, exposição de fotografias, objetos trazidos das diversas viagens, cartas trocadas entre o casal, outros familiares e amigos, objetos pessoais e 0 marcante vestuário do escritor (camisas muito estampas e coloridas) (Figuras 7 e 8 ). A exibição de áudio que conta os momentos vivenciados por aquelas paredes desde os mais simples, como a visita de amigos, às efervescentes discussões políticas e culturais, a criação literária e as festas com roda de música, é mais uma das técnicas utilizadas para traduzir a essência do lugar. O cheiro de pimenta recebe o visitante ao adentrar a cozinha, equipada com utensílios utilizados por seus moradores, imitação de pratos culinários descritos nas obras do escritor, especiarias que podem ser cheiradas e experimentadas e várias referências a personagens (Figura 9). Neste cômodo, há ainda a projeção de vídeos que mostram Dadá, uma famosa cozinheira baiana, preparando receitas citadas nos romances amadianos (Figura 10). Já na biblioteca, além das edições dos livros do casal de escritores, há também xilogravuras espalhadas pelas paredes e exibição de animações que resumem as tramas escritas pelo escritor baiano. Em uma das varandas é possível apreciar a diversificada exposição de arte popular do casal, com peças colecionadas ao longo de cinquenta anos e provenientes de diversas partes do mundo. Jorge Amado gostava de sapos, por isso é possível encontrá-los, nos mais diversos tamanhos e materiais, ao longo da visita, que termina no jardim. Neste lugar, 
há uma escultura forjada em ferro de Exu³ (Figura 11), santo orixá guardião da casa, além de quiosques com exibição de documentários, árvores plantadas pelos escritores e os bancos de alvenaria cobertos por mosaicos de cacos de azulejo, onde o casal costumava sentar e mangueira onde foram depositadas suas cinzas (Figura 12). Caso o visitante não queira a ajuda do guia-intérprete, é possível se aventurar pela casa e descobrir cada detalhe, com a ajuda de placas interpretativas e todos os outros recursos disponíveis.

Figura 5. Sala de estar

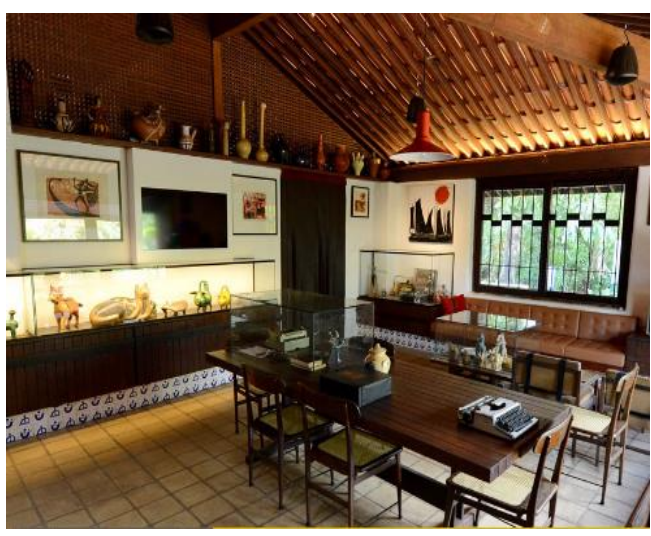

Fonte: casadoriovermelho.com.br.

Figura 7. Quarto de Jorge Amado e Zélia Gatai, nas paredes projeção de ilustrações que fazem parte dos romances do escritor

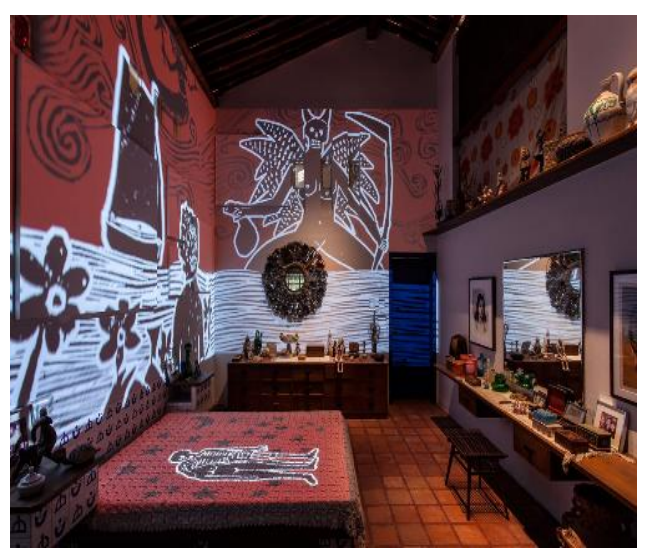

Fonte: casadoriovermelho.com.br.
Figura 6. Baú, destaque para a pintura de Floriano Teixeira (óleo sobre madeira) e livros do escritor

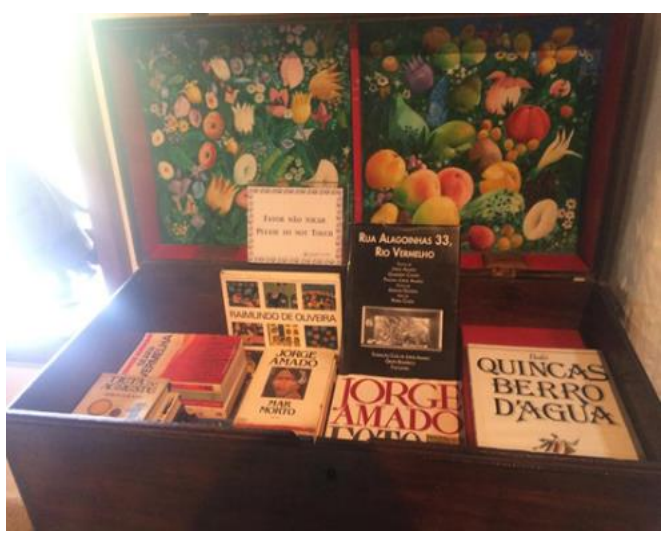

Fonte: Crédito fotográfico Juliana Menezes.

Figura 8. Exposição das camisas do escritor

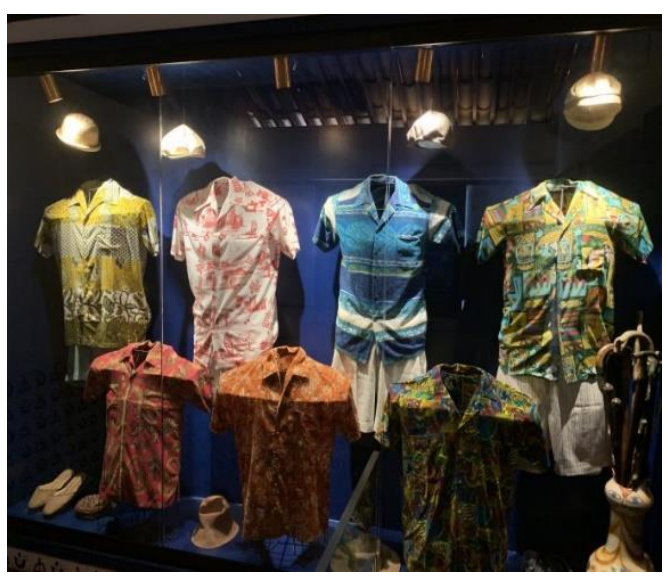

Fonte: diariodesalvador.com.

\footnotetext{
3 "Divindade da mitologia yoruba de grande poder, que simboliza o movimento. Exu transita entre a vida e a morte, o bem e o mal, enfim, está entre hemisférios, como o mestiço e o malandro, figuras frequentes na obra amadiana" (Goldstein, 2002: 114).
} 
Figura 9. Cozinha

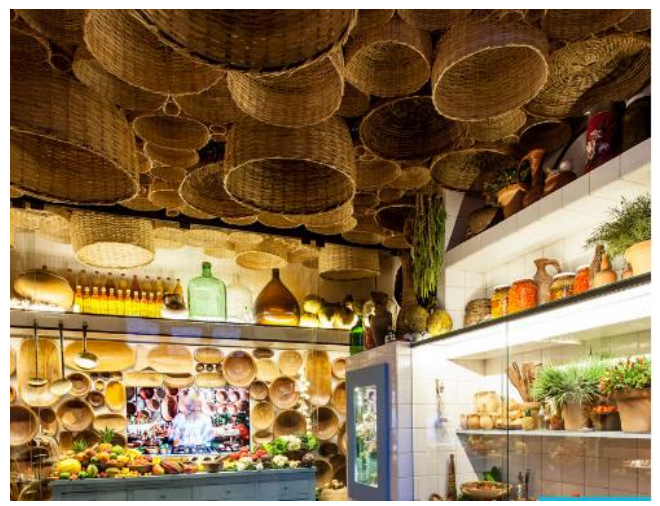

Fonte: casadoriovermelho.com.br.

Figura 11. Exu, santo orixá guardião da Casa, escultura em ferro do artesão Mestre Manu

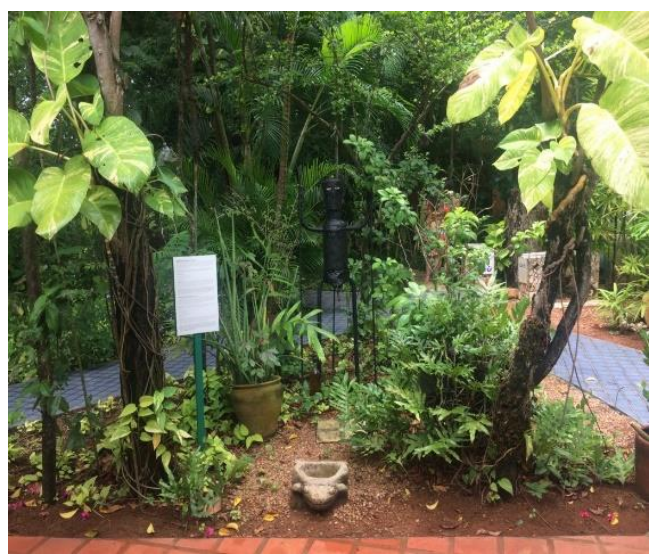

Fonte: Crédito fotográfico Juliana Menezes
Figura 10. Cozinha - Exibição de vídeo da baiana Dadá

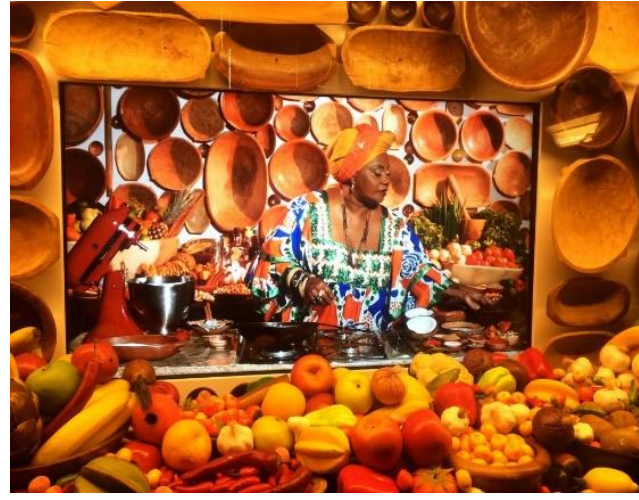

Fonte: Crédito fotográfico Juliana Menezes.

Figura 12. Jardim, com destaque para os bancos onde o casal costumava sentar e mangueira onde foram depositadas suas cinzas

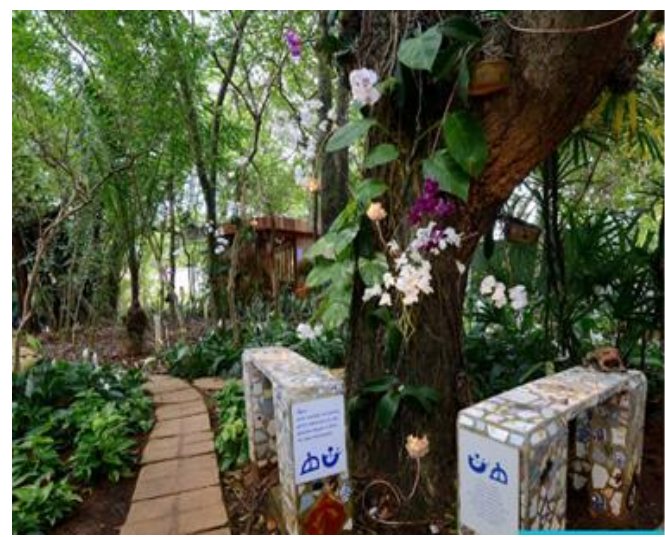

Fonte: casadoriovermelho.com.br.

Como visto, várias das técnicas de interpretação do patrimônio foram utilizadas, juntamente com a interpretação ao vivo, no intuito de apresentar a Casa de maneira viva e autêntica. Em consonância com as ideias de Tilden (2007), que afirma que interpretar o patrimônio possui, ao mesmo tempo, um pouco de arte e de ciência, pode-se notar os diferentes recursos tecnológicos e artísticos utilizados para estimular os sentidos (música, pintura, filme, escultura, literatura, a arte em diferentes formas). Tais procedimentos proporcionam uma experiência única aos turistas e residentes, sem desconsiderar o valor científico das informações (baseadas não só nas memórias da família, mas também em estudos sobre o autor e sua obra), contribuindo para a valorização dos bens culturais e para o desenvolvimento do turismo cultural sustentável. 


\section{Considerações finais}

Em tempos de crescente globalização, a proteção, preservação, interpretação e promoção do patrimônio cultural de diferentes regiões têm sido pontos fundamentais para a valorização das culturas locais, contribuindo também para o desenvolvimento sustentável.

Nessa perspectiva, o turismo cultural sustentável funciona como um elo entre turismo e preservação, capaz de promover a restauração, a revitalização, a ressignificação e a reconfiguração do patrimônio que, se bem interpretado, cria oportunidades de aprendizado para turistas e moradores, os quais passam a conhecer os valores, os costumes, a história e a identidade através do patrimônio. Isso promove a comunidade e desenvolve a cidadania cultural.

Do ponto de vista econômico, esse tipo de turismo tem beneficiado regiões com o aumento do fluxo de turistas, que incrementa a captação de recursos, gerando mais empregos e renda para a comunidade e, em consequência, atraindo outras alternativas de desenvolvimento econômico.

Assim, cidades que possuem bens relacionados a algum aspecto da cultura têm promovido a sua recuperação e preservação, transformando-os em grandes motivos para atrair os turistas. No Brasil, existem alguns casos de restauração de bens patrimoniais que foram aproveitados como recursos turísticos, impulsionando a sua integração ao quadro econômico do local e, paralelamente, melhorando a qualidade de vida de seus habitantes. A reconfiguração da casa-museu Casa do Rio Vermelho é um exemplo desse tipo de promoção do patrimônio.

A literatura, sendo um elemento cultural que influencia e é influenciado pela história (Simões, 1998), também se constitui como motivo para atrair o turista a uma localidade que foi ficcionalizada. Em Salvador, a Casa do Rio Vermelho, compreendida aqui não só como um lugar de memória, mas também como um lugar literário, tem atraído milhares de turistas, em virtude de ter sido a residência de Jorge Amado, escritor que soube retratar na sua obra literária fatos históricos, hábitos, costumes, o cotidiano e a identidade da Bahia, tornando-a famosa mundialmente. A Casa, hoje, configura-se como um lugar que dispõe de potencialidades que permitem o desenvolvimento de um turismo cultural sustentável.

A análise do funcionamento da Casa, feita a partir da observação in loco, permitiu perceber que os espaços foram reconfigurados, buscando a valorização da cultura e do turismo. Os cômodos estão apresentados de forma que se aproximem o máximo possível da época em que Jorge Amado e Zélia Gatai moravam no lugar, para tanto, estratégias foram pensadas visando à informação de sua história de maneira criativa e viva. Os bens culturais, assim, estão valorizados não só sob o ponto de vista estético e de consumo, mas, principalmente, devido ao seu valor de significado, transmitindo traços culturais e identitários para as gerações mais novas e incentivando a leitura dos livros do casal. A interpretação do patrimônio utilizada no lugar é compreendida como uma aliada do desenvolvimento sustentável, promovendo um turismo cultural sustentável no qual os turistas são motivados a desvendar e conhecer melhor a história do lugar, os bens culturais são preservados e a economia, equilibrada. 


\section{Referências}

Amado, J. (1999). Boa notícia logo pela manhã. In Fundação Jorge Amado (Ed.), Rua Alagoinhas 33, Rio Vermelho: A casa de Zélia e Jorge Amado. Textos de Jorge Amado, Gilberbert Chaves e Paloma Jorge Amado. Fotos de Adenor Gondim. Arte de Pedro Costa (pp. 14-16). Salvador: Fundação Casa de Jorge Amado. (pp. 14-16). Salvador: Fundação Casa de Jorge Amado.

Amado, P. (2014). Vivemos nesta casa. In a casa do Rio Vermelho - Jorge Amado e Zélia Gatai. Folheto informativo do museu (p. 1). Salvador: Fundação Casa de Jorge Amado.

Appadurai, A. (1996). Modernity at large: Cultural dimensions of globalization. Minneapolis: University of Minnesota Press.

Bissoli, M. A. M. A. (1999). Planejamento turístico municipal com suporte em sistemas de informações. São Paulo: Futura.

Chaves, G. (1999). Insinuações e fragmentos. In Fundação Jorge Amado (Ed.), In Rua Alagoinhas 33, Rio Vermelho: A casa de Zélia e Jorge Amado. Textos de Jorge Amado, Gilberbert Chaves e Paloma Jorge Amado (Fotos de Adenor Gondim. Arte de Pedro Costa) (pp. 74-85). Salvador: Fundação Casa de Jorge Amado.

Cresswell, T. (2015). Place: An introduction. United Kington: Wiley Blackwell.

Eliade, M. (1992). O sagrado e o profano. (Trad. Rogério Fernandes). São Paulo: Martins Fontes.

Emery, E. (2012). Photojournalism and the origins of the French writer house museum (1881-1914). Privacy, publicity, and personality. London \& New York: Routledge.

Goldstein, I. S. (2002). Uma leitura antropológica de Jorge Amado: Dinâmicas e representações da identidade nacional. Diálogos Latinoamericanos, 5, 109-133.

Guattari, F. (2001). As três ecologias. (Trad. Suely Rolnik). Campinas: Papirus.

Guerreiro, G. S. (2005). A cidade imaginada - Salvador sob o olhar do turismo. Gestão e Planejamento, 6(11), Salvador, 6-22.

Hall, S. (1992). A identidade cultural na pós-modernidade. (Trad. Tomaz Tadeu da Silva \&, Guaracira Lopes Louro). Rio de Janeiro: DP\&A.

Hendrix, H. (2012). Writers' houses and the making of memory. London: Routledge.

Lage, B. H. G. \& Milone, P. C. (Orgs.). (2000). Turismo: Teoria e prática. São Paulo: Atlas.

Lucas, S. M. de M. (2003). Vale a pena preservar. Turismo cultural e desenvolvimento sustentável [Notas da autora em Oficina sobre Turismo e Patrimônio Cultural, realizada pela Universidade Estadual de Santa Cruz, em Julho de 2003].

Magadán-Díaz, M. \& Rivas García, J. I. (2012). Turismo literario. Oviedo: Septem Ediciones.

Moletta, V. F. \& Goidanich, K. L. (2001). Turismo cultural. Porto Alegre: SEBRAE/RS.

Murta, S. M. \& Albano, C. (Orgs). (2002). Interpretar o patrimônio: Um exercício do olhar. Belo Horizonte: Ed. UFMG; Território Brasilis.

Murta, S. M. \& Goodey, B. (1995). Interpretação do patrimônio para o turismo sustentado: Um guia. Belo Horizonte: SEBRAE (MG).

Nora, P. (1993). Entre memória e história: A problemática dos lugares. (Trad. Yara Aun Khoury). Projeto História, 10, 7-28. São Paulo: PUC-SP.

Pérez, X. P. (2009). Turismo cultural: Uma visão antropológica. (Coleção Pasos Edita, n. 2). Tenerife: Asociación Canaria de Antropología. doi: 10.11606/issn.1984-4867.v25i2p497-499

Pitombo, J. P. (2014, 4 fevereiro). Casa de Jorge Amado e Zélia Gattai será transformado em museu em Salvador. Folha de São Paulo llustrada. Disponível em https://m.folha.uol.com.br/ilustrada/2014/02/1406993-casa-de-jorge-amado-e-zelia-gattai-seratransformado-em-museu-em-salvador.shtml 
Póvoas, R. C. (1989). A linguagem do candomblé: Níveis sociolinguísticos de integração afro-portuguesa. Rio de Janeiro: José Olímpio.

Quinteiro, S. \& Baleiro, R. (2019). Estudos em literatura e turismo: Conceitos fundamentais. Lisboa: Universidade de Lisboa. Faculdade de Letras. Centro de Estudos Comparatistas Faculdade de Letras.

Richards, G. (2000). Cultural tourism: Challenges for management and marketing. In William C. Gartner \& David W. Lime (Eds.), Trends in outdoor recreation, leisure and tourism (pp. 187-196). Wallingford: CABI Publishing.

Richards, G. (2009). Turismo cultural: Padrões e implicações. In de Camargo, P. \& da Cruz, G. (Eds.), Turismo Cultural: Estratégias, sustentabilidade e tendências (pp. 25-48). Bahia: UESC.

Simões, M. L. N. (1998). As razões do Imaginário. Salvador: FCJA/Editus.

Simões, M. L. N. (2018). Pluralidades: Patrimônio cultural e viagem - Relendo a literatura sul-baiana. Ilhéus: Editus.

Tilden, F. (2007). Interpreting our heritage. Chapel Hill: The University of North Carolina Press.

Tripadvisor. (2019). Avaliação de visitantes. Disponível em https://www.tripadvisor.pt/ShowUserReviews-g303272-d7262898-r599391555Casa_do_Rio_Vermelho-Salvador_State_of_Bahia.html

Tude de Sá, A. Q. G. (2018). Um "lugar de memória" e seus objetos: A construção de um museu imaginário. Revista Iberoamericana de Turismo - RITUR, Penedo, 8(4), 218-232. doi: 10.2436/20.8070.01.98

Urry, J. (1996). O olhar do turista: Lazer e viagens nas sociedades contemporâneas. São Paulo, Studio Nobel/SESC.

Veverka, J. (2018). Interpretive master planning. Volume one: Strategies for the New Millennium. Edinburgh: Museums etc.

JULIANA MENEZES é doutoranda em Estudos Portugueses pela Universidade Nova de Lisboa. É professora de Língua Portuguesa do Instituto Federal da Bahia (Brasil) e investigadora do Núcleo de Estudos e Pesquisas Urbanos e Culturais do Sul da Bahia (NEPUC-SB), do Instituto de Estudos em Literatura e Tradição (IELT) e do Centro de Estudos Comparatistas (CEC). Suas áreas de interesse são literatura, cultura e turismo. Ciência ID: B81FC2636991. Endereço institucional: Departamento de Estudos Portugueses, Faculdade de Ciências Sociais e Humanas, Universidade Nova de Lisboa, Lisboa, 1069-061, Portugal.

Submetido em 12 fevereiro 2020

Aceite em 2 maio 2020 